\title{
Esophageal schwannoma: a case report
}

\author{
Masahiro Kitada ${ }^{1 *}$, Yoshinari Matsuda ${ }^{1}$, Satoshi Hayashi ${ }^{1}$, Kei Ishibashi ${ }^{1}$, Kensuke Oikawa ${ }^{2}$ and Naoyuki Miyokawa ${ }^{2}$
}

\begin{abstract}
Most tumorous lesions of the esophagus are esophageal cancers. Benign primary tumors of the esophagus are uncommon, and account for approximately $2 \%$ of all esophageal tumors. More than $80 \%$ of benign esophageal tumors are leiomyomas, with schwannomas being rare. A 55-year-old woman visited our internal medicine department with complaints of palpitations and discomfort during swallowing. A chest computed tomography scan showed a lobulated tumor $(75 \times 57 \times 80 \mathrm{~mm})$ in the upper to middle mediastinum, with homogenous inner opacity, compressing the esophagus. Upper gastrointestinal endoscopy revealed a smooth-surfaced elevated lesion covered with normal mucosa, and a schwannoma was diagnosed based on the biopsy result. The tumor was large. It was thus considered to be difficult to repair the esophagus by direct anastomosis after tumor resection.

Therefore, subtotal esophagectomy and esophagogastrostomy in the right thorax were performed. Histopathological examination revealed spindle-shaped cells in a fasciculated and disarrayed architecture and nuclei in a palisading pattern. Immunohistochemical studies revealed S100 protein positivity and the absence of staining for a smooth muscle actin (aSMA), CD34 and CD117, thereby establishing the diagnosis of benign schwannoma. Her postoperative course was uneventful and there has been no evidence of recurrence to date.
\end{abstract}

\section{Background}

The incidence of benign primary tumors of the esophagus is low. Most are leiomyomas, and schwannomas are rare. We report a patient with schwannoma who was referred to us for evaluation of a mediastinal tumor. Detailed examination yielded a diagnosis of schwannoma arising from the esophageal submucosa and radical surgery was performed.

\section{Case presentation}

A 55-year-old woman visited our hospital with complaints of palpitations and discomfort during swallowing. Her medical and familial histories were unremarkable. A frontal chest radiograph showed a smooth round mass, and a lateral radiograph showed a smooth mass slightly larger than $7 \mathrm{~cm}$ in diameter in the middle mediastinum between the trachea and the vertebral bodies. A chest computed tomography (CT) scan showed a lobulated tumor $(75 \times 57 \times 80 \mathrm{~mm})$ in the upper to middle mediastinum, with a homogenous inner component, compressing the esophagus (Figure 1). Magnetic resonance imaging (MRI) of the chest revealed no invasion of surrounding

\footnotetext{
* Correspondence: k1111@asahikawa-med.ac.jp

'Department of Surgery, Asahikawa Medical University, Midorigaoka-Higashi 2-1-1-1, Asahikawa, Hokkaido 078-8510, Japan

Full list of author information is available at the end of the article
}

organs. On imaging studies, a mesenchymal tumor such as gastrointestinal stromal tumor was suspected. Upper gastrointestinal endoscopy showed a smooth elevated lesion, $22 \mathrm{~cm}$ from the incisor teeth. A mucous membrane was accompanied by the venous dilation (Figure 2). A schwannoma was diagnosed based on the biopsy result for the lesion. Although there was no evidence of malignancy, the patient underwent surgery because of the large size of the tumor, dysphagia, palpitations caused by the tumor compressing the heart, and a suspicion of malignant potential. The patient was placed in the left lateral position and underwent a mini thoracotomy via the fifth right intercostal space with thoracoscopic assistance. A mass slightly larger than $8 \mathrm{~cm}$ in diameter was found adjacent to the mid-thoracic esophagus. From above, the tissue surrounding the esophagus was detached and the tumor was excised. The resulting defect in the adventitia and muscular layer was extensive. A direct anastomosis was considered to be difficult, such that subtotal esophagectomy and esophagogastrostomy in the right thorax were performed. The resected specimen showed normal esophageal mucosa. The tumor was well demarcated and elastic hard, had a globular appearance, and measured $75 \times 57 \times 80$ $\mathrm{mm}$. The cut surface was almost uniformly milky white. Histopathological examination revealed spindle-shaped cells in a fasciculated and disarrayed architecture and
C Biomed Central

(c) 2013 Kitada et al.; licensee BioMed Central Ltd. This is an Open Access article distributed under the terms of the Creative Commons Attribution License (http://creativecommons.org/licenses/by/2.0), which permits unrestricted use, distribution, and reproduction in any medium, provided the original work is properly cited. 


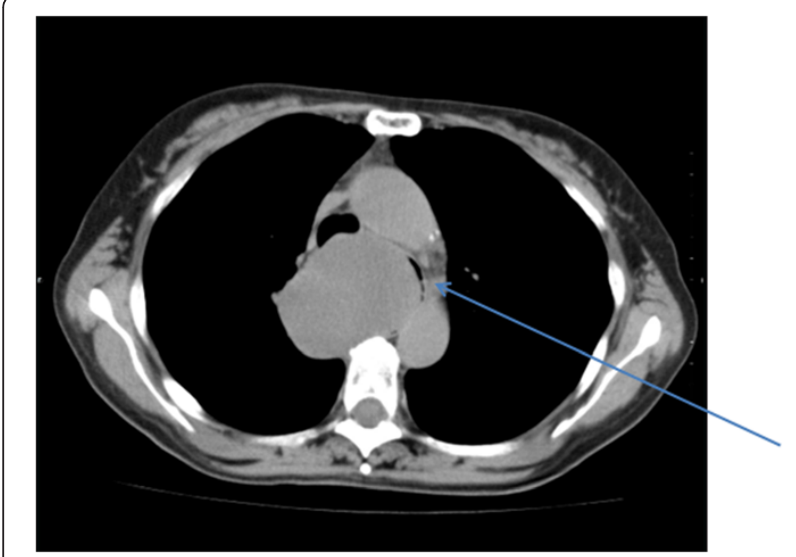

Figure 1 Chest computed tomography (CT) scan showed a lobulated tumor $(75 \times 57 \times 80 \mathrm{~mm})$ in the upper to middle mediastinum. The arrow shows compression of the esophagus.

nuclei in a palisading pattern (Figure 3). Immunohistochemical studies revealed S100 protein positivity (Figure 4) and the absence of staining for $\alpha$ smooth muscle actin ( $\alpha$ SMA), CD34 and CD117, establishing the diagnosis of benign schwannoma. Her postoperative course was uneventful and there has been no evidence of recurrence to date.

\section{Discussion}

Most tumorous lesions of the esophagus are esophageal cancers. Benign primary tumors of the esophagus are uncommon, and account for approximately $2 \%$ of all

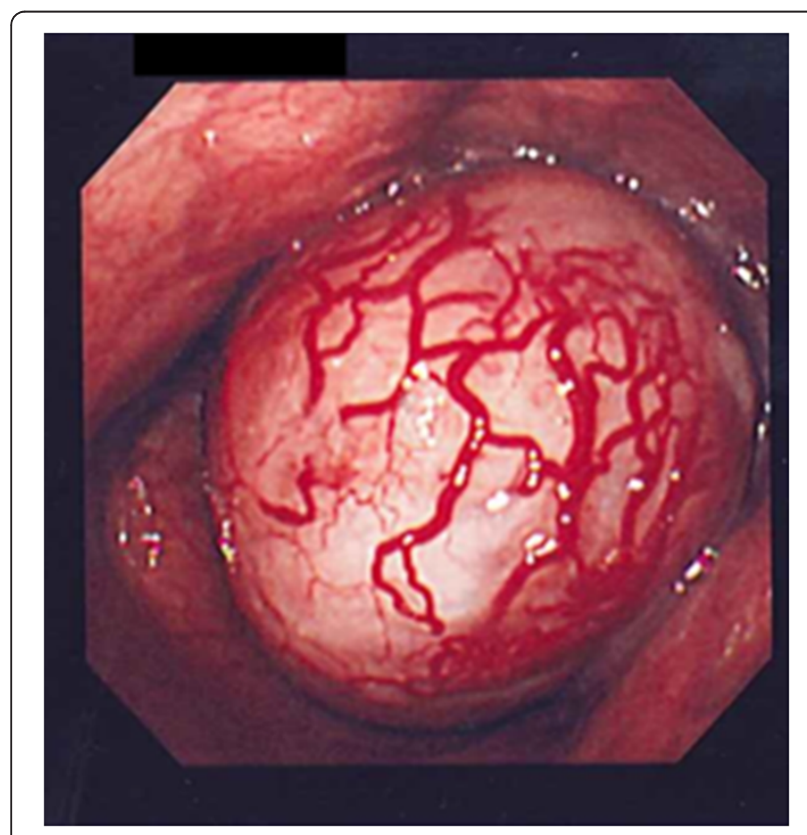

Figure 2 Upper gastrointestinal endoscopy showing a smooth elevated lesion, $22 \mathrm{~cm}$ from the incisor teeth. A mucous membrane was accompanied by the venous dilation.

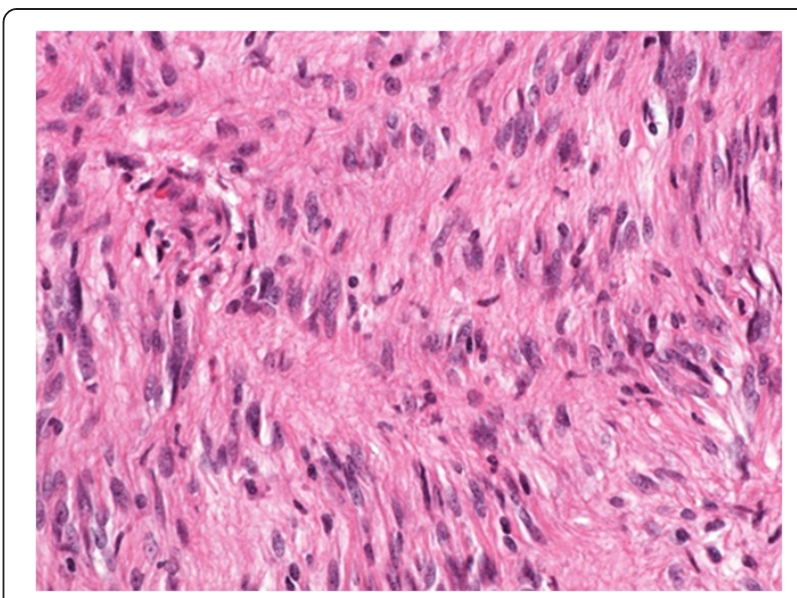

Figure 3 Histopathological findings revealed spindle-shaped cells in a fasciculated and disarrayed architecture and nuclei in a palisading pattern (hematoxylin and eosin stain, $\times 400$ ).

esophageal tumors. More than $80 \%$ of benign esophageal tumors are leiomyomas, with Schwannomas being rare $[1,2]$. Schwannoma of the esophagus more frequently develops in women than in men and these tumors are often located in the upper and mid esophagus in the mid mediastinum. A preoperative diagnosis of this condition is difficult, and the definitive diagnosis is often established after resection [3]. A schwannoma that developed in the posterior mediastinum was reported [4]. Furthermore, a patient with a malignant schwannoma has also been reported, but such cases are extremely rare [5].

Symptoms of this disease include dysphagia, dyspnea, and chest pain, and are likely to appear and worsen as the schwannoma increases in size [6]. Fluorodeoxyglucose positron emission tomography as well as CT and MRI are reportedly useful for the confirmation of mediastinal tumors [7]. However, diagnosing a schwannoma is

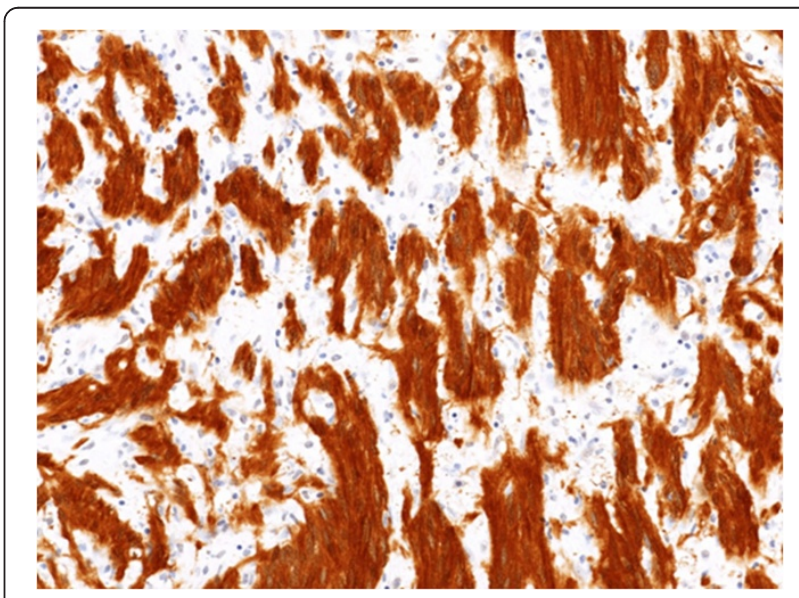

Figure 4 Immunohistochemical studies revealed S100 protein positivity $(\times 200)$. 
difficult with only imaging studies. In our present case as well, the results from the biopsy obtained with esophagogastroendoscopy were necessary for establishing the diagnosis. Schwannoma is a submucosal tumor, and endoscopic ultrasonography-guided fine needle aspiration biopsy is reportedly useful for both diagnosis and management [8].

In general, histological features of schwannoma include spindle-shaped tumor cells arranged in a palisading pattern or with loose cellularity in a reticular array. Immunohistochemical stainings for S100 protein, aSMA, CD34 and CD117 are also useful [9].

Chemotherapy and radiation therapy are ineffective such that surgical excision including the capsule is indicated for symptomatic cases and also for those with possibly malignant schwannoma. The use of enucleation with video-assisted thoracoscopic surgery is becoming common for small tumors $(\leq 2 \mathrm{~cm})$ [3]. However, for large tumors $(\geq 8 \mathrm{~cm})$ with broad areas adjacent to the esophageal muscular layer, the mucosal defect becomes extensive, and esophagectomy and esophagogastrostomy are thus usually performed [10]. In our present case, the tumor was approximately $8 \mathrm{~cm}$ in diameter, and the defect of the adventitia and muscular layer was extensive after tumor excision. Thus, direct anastomosis was considered to carry an increased risk for complications including anastomotic leakage and esophageal stricture. Therefore, esophagectomy and esophagogastrostomy were performed. Her postoperative course was uneventful. She had neither postoperative stricture nor problems with eating and drinking. This favorable outcome confirmed the procedure to have been appropriate.

\section{Conclusions}

Here, we report a relatively rare case of schwannoma of the esophagus, initially identified as a large mediastinal tumor. The tumor was $80 \mathrm{~mm}$ in diameter and the postresection defect of the adventitia and muscular layer was extensive. Esophagectomy and esophagogastrostomy were thus performed and good postoperative recovery was achieved.

\section{Consent}

Written informed consent was obtained from the patients for publication of this case report and any accompanying images. A copy of the written consent is available for review by the Editor-in-Chief of this journal.

\section{Competing interests}

The authors declare that they have no competing interests.

\section{Authors' contributions}

MK operated on this case and analyzed all data. YM, SH and KS assisted with the operation. KO and NM diagnosed the pathology of this case. All authors read and approved the final manuscript.

\section{Author details}

'Department of Surgery, Asahikawa Medical University, Midorigaoka-Higashi 2-1-1-1, Asahikawa, Hokkaido 078-8510, Japan. ²Department of Clinical Pathology, Asahikawa Medical University, Asahikawa, Japan.

Received: 19 February 2013 Accepted: 22 September 2013 Published: 2 October 2013

\section{References}

1. Matsuki A, Kosugi S, Kanda T, Komukai S, Ohashi M, Umezu H, Mashima Y, Suzuki T, Hatakeyama K: Schwannoma of the esophagus: a case exhibiting high 18F-fluorodeoxyglucose uptake in positron emission tomography imaging. Dis Esophagus 2009, 22:E6-E10.

2. Mizuguchi S, Inoue K, Imagawa A, Kitano Y, Kameyama M, Ueda H, Inoue Y: Benign esophageal schwannoma compressing the trachea in pregnancy. Ann Thorac Surg 2008, 85:660-662.

3. Park BJ, Carrasquillo J, Bains MS, Flores RM: Giant benign esophageal schwannoma requiring esophagectomy. Ann Thorac Surg 2006, 82:340-342.

4. Dutta R, Kumar A, Jindal T, Tanveer N: Concurrent benign schwannoma of oesophagus and posterior mediastinum. Interact Cardiovasc Thorac Surg 2009, 9:1032-1034

5. Wang S, Zheng J, Ruan Z, Huang H, Yang Z, Zheng J: Long-term survival in a rare case of malignant esophageal schwannoma cured by surgical excision. Ann Thorac Surg 2011, 92:357-358

6. Tokunaga T, Takeda S, Sumimura J, Maeda H: Esophageal schwannoma: a case report. Surg Today 2007, 37:500-502.

7. Toyama E, Nagai Y, Baba Y, Yoshida N, Hayashi N, Miyanari N, Baba H: A case of thoracoscopically resected benign esophageal schwannoma with high uptake on FDG-PET. Esophagus 2008, 5:167-170.

8. Kinoshita K, Isozaki K, Tsutsui S, Kitamura S, Hiraoka S, Watabe K, Nakahara M, Nagasawa Y, Kiyohara T, Miyazaki Y, Hirota S, Nishida T, Shinomura Y, Matsuzawa $Y$ : Endoscopic ultrasonography-guided fine needle aspiration biopsy in follow-up patients with gastrointestinal stromal tumours. Eur J Gastroenterol Hepatol 2003, 15:1189-1193.

9. Kobayashi N, Kikuchi S, Shimao H, Hiki Y, Kakita A, Mitomi H, Ohbu M: Benign esophageal schwannoma: a case report. Surg Today 2000, 30:526529

10. Davis EA, Heitmiller RF: Esophagectomy for benign disease: trends in surgical results and management. Ann Thorac Surg 1996, 62:369-372.

doi:10.1186/1477-7819-11-253

Cite this article as: Kitada et al.: Esophageal schwannoma: a case report. World Journal of Surgical Oncology 2013 11:253.

\section{Submit your next manuscript to BioMed Central and take full advantage of:}

- Convenient online submission

- Thorough peer review

- No space constraints or color figure charges

- Immediate publication on acceptance

- Inclusion in PubMed, CAS, Scopus and Google Scholar

- Research which is freely available for redistribution 